\title{
Application of edible film incorporated with Portulaca oleracea extract to inhibit microbiological and oxidative damage in sausages
}

\author{
BINTI QOEROTI, ARTINI PANGASTUTI ${ }^{\vee}$, ARI SUSILOWATI \\ Graduate Program of Bioscience, Faculty of Mathematics and Natural Sciences, Universitas Sebelas Maret, Jl. Ir. Sutami 36A, Surakarta 57 126, Central \\ Java, Indonesia. Tel.: +62-271-646994, Fax.: +62-271-646655, •email: artini_p@ staff.uns.ac.id
}

Manuscript received: 6 July 2021. Revision accepted: 29 July 2021.

\begin{abstract}
Qoeroti B, Pangstuti A, Susilowati A. 2021. Application of edible film incorporated with Portulaca oleracea extract to inhibit microbiological and oxidative damage in sausages. Biodiversitas 22: 3556-3561. Environmental pollution by plastic from food packaging can be reduced by applying edible film as a biodegradable casing and safe for consumption. Utilization of Indonesia's biodiversity, especially purslane plants (Portulaca oleracea L.) at Boyolali, Central Java, Indonesia as an antimicrobial compound that can improve the quality of chitosan edible films. This study aims to determine the effect of purslane extract (Portulaca oleracea L.) as an antibacterial, antifungal, and antioxidant agent in edible films in inhibiting microbiological and oxidative damage to sausages. The film was made by mixing the extract $(0 \% ; 2.5 \% ; 5 \% ; 10 \%)$ into the chitosan solution and sorbitol, then applied to casing the sausage. The sausage was then stored at room temperature $(27 \mathrm{C})$ and in refrigerator $\left(4^{\circ} \mathrm{C}\right)$. Sausage quality testing was carried out on days $0 ; 3$; 6; 9; 12; 15 during storage, including determination of Total Plate Count, Yeast Mold Count, and thiobarbituric acid test. The results of tensile strength, water vapor permeability, elongation, antioxidant, FTIR film, and morphology observed by using SEM of the films with and without the purslane extract addition were different. After 15 days of storage, Kruskal-Wallis analysis also revealed that the addition of purslane extract significantly inhibited the growth of microorganisms and oxidative damage to sausages.
\end{abstract}

Keywords: Chitosan, edible films, Portulaca oleracea, sausage, sorbitol

\section{INTRODUCTION}

Food packaging is crucial to ensure that product quality is maintained during the storage period until consumers safely accept it. Nevertheless, the use of non-biodegradable plastic as a casing, in this case, sausage, can cause environmental problems; thus, it is necessary to apply environmentally friendly packaging while maintaining the quality of sausage products. One of the environmentally friendly packagings that have been applied in the packaging of food products is edible film. The edible film is a thin layer made of biopolymer, which is edible and biodegradable (Campos et al. 2011; Youssef et al. 2017).

However, some factors affect the quality of food packaged with edible films, including the presence of contaminants, both from bacteria and fungi. Thus, other additional compounds are needed in the film, such as natural compounds containing antimicrobial, antifungal, and antioxidant compounds (Quirós-Sauceda et al. 2014). Direct contact between the active compounds in edible films and food products reduces unwanted microbiological activity because they are able to react with other components such as fats and proteins contained or dissolved in the food matrix (Widaningrum et al. 2015). The advantages of edible films incorporating antimicrobial, antifungal and antioxidant compounds can improve the quality of edible films in packaging while preserving food and medicine. The use of active compounds from plant extracts as additives for edible films include the new filmforming materials such as plant residues, flours and gums to show their protective effectiveness and suitability in various types of foods (Galus et al. 2020), the use of essential oils as natural antimicrobial and antioxidant compounds to obtain bioactive films or coatings (Gonzalez et al. 2011). For this reason, flavonoids and alkaloids in purslane extract (Portulaca oleracea L.) as antibacterial, antifungal, and antioxidant compounds can capture free radicals, such as 1,1-diphenyl-2-picryl hydazyl (DPPH) (Indradewi et al. 2018). Purslane extract has been widely used in food products because purslane is a type of vegetable in several regions of Indonesia and other countries so it has been proven non-toxic and safe for consumption. In addition to the use of purslane extract as a medicinal and vitamin ingredient, purslane extract has been used for the manufacture of sweets, herbal drinks, snacks from purslane leaves, yogurt, and jelly candy (Chen et al. 2019; Shanker et al. 2019; Handayani et al. 2020; Anli et al. 2021). In addition, the making of edible films containing active compounds further enhances its function as a barrier compared to spraying or food immersion methods (Alves et al. 2011; Bourbon et al. 2011). So far, there have been no studies on edible films with the addition of $P$. oleracea extract as sausage casing. Therefore, this study aimed to determine the effect of adding purslane extract to chitosan edible film in preventing microbiological and oxidative damage to sausages. 


\section{MATERIALS AND METHODS}

\section{Extraction and production of edible film}

Purslane was obtained from Central Java, Indonesia, area. The whole part of the healthy purslane was used for extraction using the maceration method with $80 \%$ ethanol as solvent. The procedure for edible film making refers to the studies of Purwanti (2010) and Katili et al. (2013), with modifications. Chitosan solution 2\% (v/v) (HiMedia, India) was mixed with $2 \%$ sorbitol (HiMedia, India) as a plasticizer. Purslane extract with concentrations of $0 \%$, $2,5 \%, 5 \%$, and $10 \%$ was added to the mixture.

\section{Physical, chemical, and morphological characterization}

The tensile strength and elongation at break tests were measured according to Bourbon et al. (2011) method using a mechanical universal testing machine (AND MCT-2150). For the Water Vapor Permeability (WVP) transmission test, the method refers to Sobral et al. (2001), with modifications. Meanwhile, Fourier-Transform Infrared Spectroscopy (FTIR) analysis utilizing the Shimadzu type feature 8201 was carried out according to Bourbon et al. (2011) method. Further, the film's surface morphology was viewed employing a Scanning Electron Microscope (SEM fei quanta 250) at the Integrated Mathematics and Natural Sciences Laboratory, Universitas Sebelas Maret.

\section{Edible film bioactivity characterization}

Antibacterial and antifungal activity tests were performed with the method from Gomes et al. (2019), using Escherichia coli, Staphylococcus aureus from the culture collection at the Microbiology Laboratory, Faculty of Medicine, Universitas Sebelas Maret, and Aspergillus niger from the culture collection at the Microbiology Laboratory, Faculty of Medicine, Universitas Gadjah Mada. The edible film was cut with a diameter of $0.5 \mathrm{~cm}$, then placed on the surface of Muller Hinton Agar (HiMedia, India) media for antibacterial testing and $1 \times 1$ $\mathrm{cm}^{2}$ on Potato Dextrose Agar (Oxoid, United Kingdom) media for antifungal testing. Antibacterial activity was observed after 24 hours of incubation at $37^{\circ} \mathrm{C}$ at the bottom of the edible film, while antifungal activity was observed after five days of incubation at $27^{\circ} \mathrm{C}$. The inhibition zone due to antibacterial and antifungal activity can be seen from the clear area at the bottom of the edible film after removal (Gomes et al. 2019). The antioxidant activity test of edible films containing purslane extract was carried out employing the DPPH method (1,1-diphenyl-2-picryl hydazyl), referring to Indradewi et al. (2018).

\section{Edible film application as sausage casing}

A total of 4 grams of cooked minced meat that had been seasoned cased using chitosan-edible film with the addition of purslane extract $0 \%, 2,5 \%, 5 \%$, and $10 \%$. Each variation of the edible film was carried out in three repetitions. The packaged sausages were further divided into two different treatments: storage at refrigerator temperature $\left( \pm 4^{\circ} \mathrm{C}\right)$ and room temperature $\left( \pm 27^{\circ} \mathrm{C}\right)$. Then, quality analysis was carried out on days $0,3,6,9,12$, and 15 during storage, including the calculation of the total plate count of bacteria referring to Atma (2016), the yeast mold counts according to Rakhmawati and Musdholifah (2019), and oxidative damage by determining the number of TBA (Thiobarbutic Acid) following Farbod et al. (2013). The data were then analyzed utilizing SPSS software with Kruskal-Wallis nonparametric analysis to see the treatment variations' effects on sausage quality. For the organoleptic test, it was conducted on day 0 of storage of sausage casing in edible film to determine consumer ratings of the product that had been produced, including the 30 panelists' preferences for the color, aroma, taste, and texture or elasticity of sausage casing in the edible film with and without the addition of purslane extract.

\section{RESULTS AND DISCUSSION}

Table 1 shows that the addition of purslane extract increased the tensile strength value and decreased the percent elongation of the edible film. The overall value of tensile strength and percent elongation has met the standard of the edible film according to the Japanese Industrial Standard (JIS) 1975.

The addition of purslane extracts also affected the amount and density of chitosan bonds in the edible film to interfere with the bonding of chitosan molecules with other ingredients in the edible film. On the other hand, the addition of extracts into the edible film could reduce the film's elasticity and reduce the bond's density in the film (Estiningtyas et al. 2012).

Table 1. Comparison of chitosan edible film characters with the addition of purslane extract with standard edible film according to Japanese Industrial Standard (JIS) 1975

\begin{tabular}{|c|c|c|c|c|c|}
\hline \multirow{2}{*}{ Characteristics } & \multirow{2}{*}{ JIS standard value } & \multicolumn{4}{|c|}{ Edible film with addition of purslane extract } \\
\hline & & $\mathbf{0 \%}$ & $2,5 \%$ & $5 \%$ & $10 \%$ \\
\hline Thickness (mm) & 0.25 & 0.27 & 0.27 & 0.27 & 0.27 \\
\hline Tensile Strength (MPa) & 0.392 & 0.84 & 0.85 & 0.86 & 1.06 \\
\hline \multirow[t]{2}{*}{ Elongation $(\%)$} & $\mathrm{Bad}<10$ & & & & \\
\hline & Good $>70$ & 190 & 96 & 88 & 13 \\
\hline Young's modulus (MPa) & 0.35 & 0.21 & 0.27 & 0.68 & 1.45 \\
\hline Water vapor transmission $\left(\mathrm{g} / \mathrm{m}^{2} \mathrm{~h}\right)$ & 7 & 6.73 & 7.88 & 8.54 & 15.06 \\
\hline
\end{tabular}


The higher the addition of purslane extract, the higher the WVP value of each film, indicating the higher the water vapor permeability. According to JIS (1975), a good edible film has a maximum water vapor permeability value of 7 $\mathrm{g} / \mathrm{m}^{2} \mathrm{~h}$. Hence, the edible film with the extract addition had a WVP value that did not meet the standard. On the other hand, the addition of purslane extract resulted in a reasonably high WVP value because more substances added to the film could increase the value of water vapor permeability (Sobral et al. 2001).

Fourier-transform infrared spectroscopy (FTIR) analysis (Figure 1) displayed that the film's absorption pattern was almost the same with and without the addition of purslane extract. Infrared spectra test measured by FTIR revealed the presence of bonds $\mathrm{CO}, \mathrm{C}_{3}-\mathrm{OH}, \mathrm{OH}, \mathrm{CH}_{2}, \mathrm{~N}$ $\mathrm{CH}_{3}, \mathrm{C}=\mathrm{O}$, $-\mathrm{OH}, \mathrm{CO}$, and $-\mathrm{NH}_{2}$, which are chemical bonds that make up chitosan, sorbitol, alkaloids, and flavonoids as the most dominant active compound in purslane extract (Yudha Karlina 2013; Zhou et al. 2015; Du et al. 2017; Indradewi et al. 2018). The number of peaks from the film with the addition of purslane extract was less because of the more ingredients.

Moreover, SEM (Scanning Electron Microscope) analysis at a magnification of 500 micrometers (Figure 2) exhibited that the edible film with the addition of purslane extract had a smoother morphology than without the extract but grains were visible on the surface. The grains on the film surface with the purslane extract addition were thought to be caused by the extract that had not been fully integrated with other ingredients in the edible film. It caused the percent elongation of the film with the addition of extract to be lower than the film without the extract addition. The grains on the film surface also caused the formation of holes to reduce the film's elasticity. Although the previous filtering was carried out, the extract addition was still not homogeneously soluble with chitosan and sorbitol. In fact, flavonoids and alkaloids, the most dominant components in the purslane extract, are polar and should be easily homogeneous with chitosan dissolved in $1 \%$ acetic acid, which is also polar (Gomes et al. 2019). Likewise, sorbitol is a hydrophilic plasticizer suitable for hydrophobic film-forming materials, such as chitosan. The cause of the purslane extracts not homogeneously dissolving could be due to the other phytochemical content of the purslane extract, which is difficult to bind with other film components. Thus, it forms small lumps, in which, after going through the drying stage, grains appeared on the film surface. However, the number of grains was not too much and was located far apart.

Further, the antibacterial activity of the edible film is shown in Figure 3. There was a clear area at the bottom of the edible film on the media inoculated with $E$. coli and $S$. aureus bacteria. It proves that there were gram-positive and gram-negative antibacterial compounds in the film. On the other hand, purslane extract contains various types of secondary metabolites, such as flavonoids, alkaloids, terpenoids, and organic acids, which play essential antimicrobial roles. The antimicrobial activity of purslane extract has been proven against several test microbes, including Escherichia coli, Staphylococcus aureus, Bacillus subtilis, Aspergillus niger, and Candida sp. (Sultana and Rahman 2013; Yudha Karlina 2013; Iranshahy et al. 2017). Besides, the film without the addition of purslane extract also showed antibacterial activity since chitosan, which was the material for making this film, also had antimicrobial properties (Helander et al. 2001). The higher the concentration of purslane extract added, the clearer the area under the edible film after being removed from the media, indicating the higher the antifungal activity.

The antifungal activity against Aspergillus niger, a type of fungus that contaminates foodstuffs, was also found in all edible films. The presence of additional substances in the film in the form of purslane extract containing antimicrobial compounds, such as flavonoids and alkaloids, plays a vital role as an antifungal (Quirós-Sauceda et al. 2014). In this case, the antifungal activity of purslane extract has been proven against several tested microbes, including Aspergillus niger, Trichophyton sp., and Candida sp. (Sultana and Rahman 2013; Yudha Karlina 2013; Iranshahy et al. 2017). In the film without the addition of purslane extract, it still showed positive antifungal results because the chitosan in this film also had antimicrobial properties (Nurainy et al. 2008). From Figure 3, it can be seen that the antifungal activity of the edible film without the addition of extract was cloudier than with the extract addition. It means that the higher the concentration of purslane extract added, the clearer the area under the edible film after removal, indicating the increasing antifungal activity.

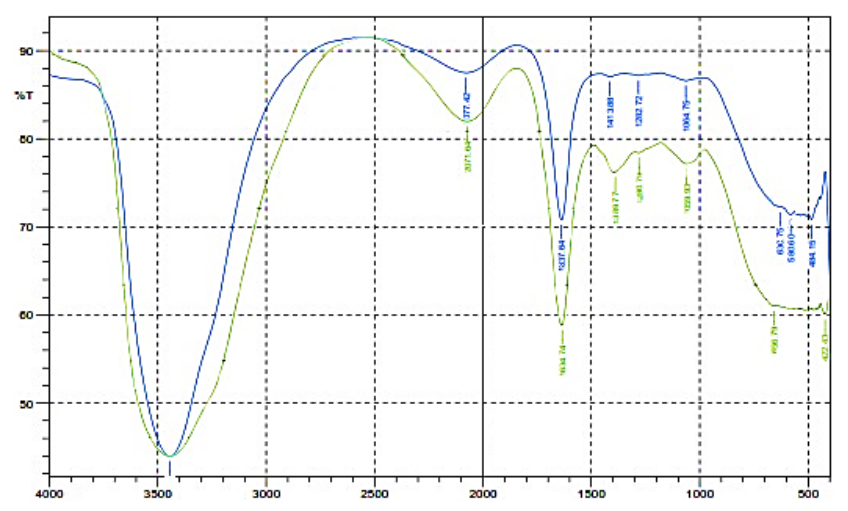

Figure 1. Fourier-Transform Infrared Spectroscopy (FTIR) on edible film without the addition of purslane extract (blue graph) and with the addition of purslane extract (green graph), with the absorption peak seen in $\%$ transmittance $(\% \mathrm{~T}): 484.15,580.6$, $630.75,1064.75,1282.72,1413.88,1637.64,2077.42,3445.98$ cm-1 (blue graph) dan 422.43, 656.79, 1059.93, 1280.79, $1389.77,1634.74,2071.64,3418.97 \mathrm{~cm}^{-1}$ (green graph) 


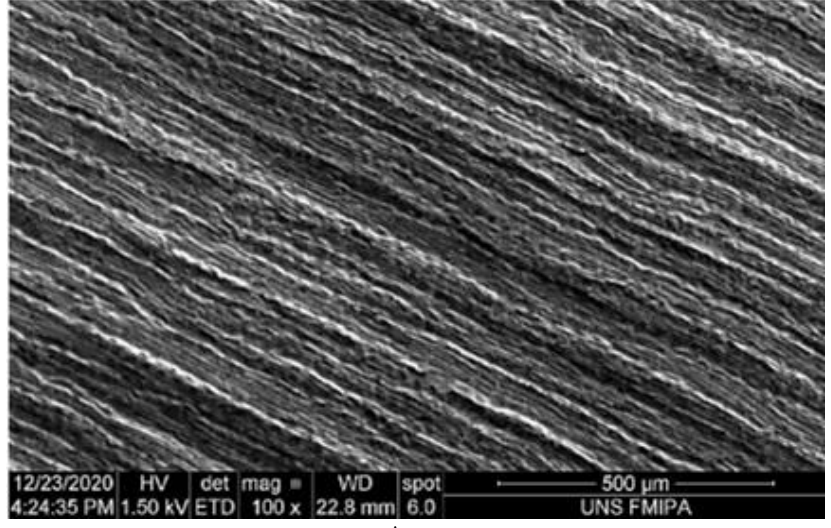

A

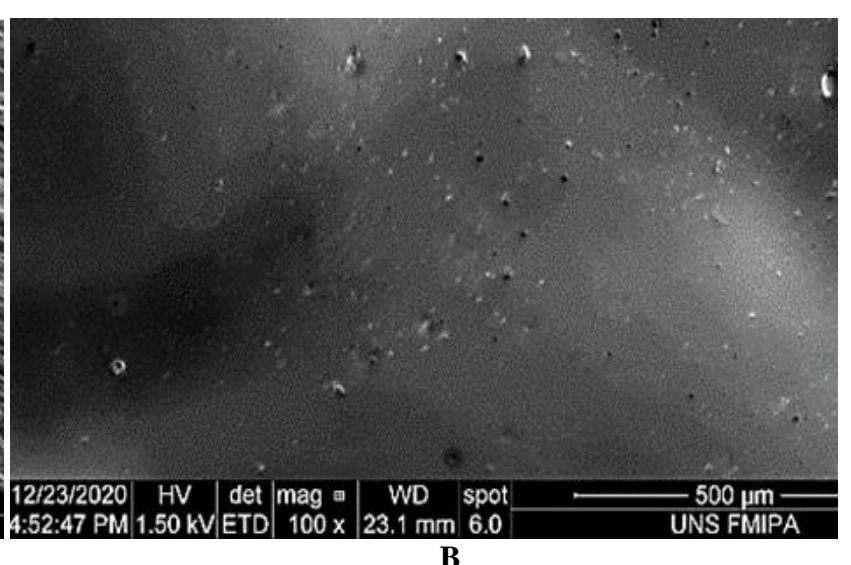

B

Figure 2. The morphology of the edible film seen utilizing SEM (Scanning Electron Microscope) at the same magnification (500 $\mu$ m) shows (A) the edible film without the addition of purslane extract is streaky, uneven, and not smooth, while (B) the edible film with the addition of purslane extract looks smooth even though there are a few grains.



A

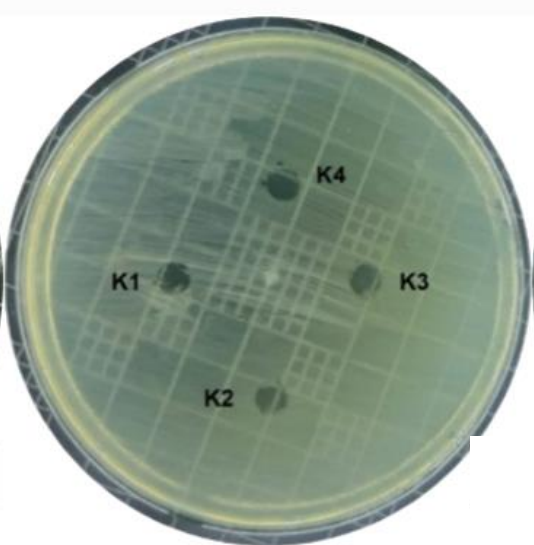

B

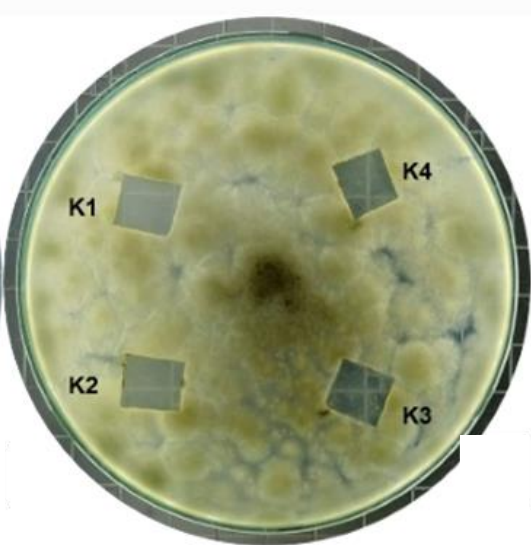

C

Figure 3. Antibacterial and antifungal activity displays a clear area under the edible film with the addition of purslane extract $0 \%$ (K1), $2.5 \%(\mathrm{~K} 2), 5 \%(\mathrm{~K} 3)$, and $10 \%(\mathrm{~K} 4)$ after being removed from the media overgrown with (A) gram-positive Staphylococcus aureus, (B) gram-negative Escherichia coli, (C) Aspergillus niger fungus.

The antioxidant activity also increased with the increasing concentration of purslane extract in the edible film (Table 2), indicating that purslane extract contains natural antioxidant compounds (Dkhil et al. 2011). Besides, the antioxidants in Portulaca oleracea extract can scavenge free radicals, such as 1,1-diphenyl-2-picryl hydazyl (DPPH) (Alam et al. 2014; Indradewi A. et al. 2018). In addition to flavonoids, endogenous antioxidant compounds in purslane are alpha-tocopherol, beta carotene, and glutathione (Sultana and Rahman 2013; Iranshahy et al. 2017).

Furthermore, the total number of sausage bacteria after 15 days of storage is shown in Table 3, the lowest at refrigerator temperature $\left(4^{\circ} \mathrm{C}\right)$ and the highest at room temperature $\left(27^{\circ} \mathrm{C}\right)$. Sausage stored at refrigerator temperature $\left(4^{\circ} \mathrm{C}\right)$ met the food requirements suitable for consumption, having total bacteria of less than $1 \times 10^{4}$ colonies/gram (BPOM 2019). It was because the edible film contains antimicrobial compounds derived from purslane extract and chitosan (Helander et al. 2001; Yudha Karlina 2013). Meanwhile, at room temperature storage, the number of bacteria that met the requirements for up to 15 days of shelf life was the only film with the addition of $5 \%$ and $10 \%$ extracts. The higher the temperature, the faster the metabolism of microbes in the sausage, causing the number of bacteria to increase. The refrigerator temperature, which is quite cold $\left(4^{\circ} \mathrm{C}\right)$, can inhibit the growth of bacteria (Atma 2016).

Table 2. Antioxidant activity of edible film

\begin{tabular}{lll}
\hline Edible film & IC50 $(\boldsymbol{\mu g} / \mathbf{m l})$ & Category \\
\hline Film with 0\% purslane extract & 461,8 & Weak \\
Film with 2,5\% purslane extract & 232,51 & Moderate \\
Film with 5\% purslane extract & 153,68 & Moderate \\
Film with 10\% purslane extract & 70,86 & Strong \\
\hline
\end{tabular}


Table 3. Total Plate Count (TPC), Yeast Mold Count (YMC), and TBA Number (Thiobarbutic Acid) on sausage casing in the edible film with the addition of $0 \%, 2.5 \%, 5 \%$, and $10 \%$ purslane extract for 15 days of storage at refrigerator temperature $\left( \pm 4{ }^{\circ} \mathrm{C}\right)$ and room temperature $\left( \pm 27^{\circ} \mathrm{C}\right)$

\begin{tabular}{|c|c|c|c|c|c|c|c|c|c|c|c|c|c|}
\hline \multirow{3}{*}{$\begin{array}{l}\text { Storage } \\
\text { Temperature }\end{array}$} & \multirow{3}{*}{ Day } & \multicolumn{12}{|c|}{$\begin{array}{c}\text { Purslane extract concentration in edible film and TPC and YMC } \\
\text { Test results (colonies/gram) and TBA (mg) of sausage }\end{array}$} \\
\hline & & \multicolumn{3}{|c|}{$\mathbf{0 \%}$} & \multicolumn{3}{|c|}{$2.5 \%$} & \multicolumn{3}{|c|}{$5 \%$} & \multicolumn{3}{|c|}{$10 \%$} \\
\hline & & TPC & YMC & TBA & TPC & YMC & TBA & TPC & YMC & TBA & TPC & YMC & TBA \\
\hline \multirow{6}{*}{$\begin{array}{l}\text { Refrigerator } \\
\text { temperature } \\
\left( \pm 4^{\circ} \mathrm{C}\right)\end{array}$} & 0 & 0 & 0 & 1.3 & 0 & 0 & 1.3 & 0 & 0 & 1.3 & 0 & 0 & 1.3 \\
\hline & 3 & 0 & 6 & 7.2 & 2 & 7 & 6.9 & 0 & 0 & 6.6 & 1 & 2 & 5.4 \\
\hline & 6 & 7 & 8 & 8.4 & 1 & 8 & 8.3 & 6 & 3 & 6.6 & 0 & 5 & 6.0 \\
\hline & 9 & 370 & 13 & 8.5 & 24 & 9 & 8.3 & 11 & 5 & 6.9 & 5 & 9 & 6.1 \\
\hline & 12 & 1360 & 30 & 10.6 & 644 & 43 & 8.5 & 14 & 6 & 8.3 & 8 & 17 & 6.3 \\
\hline & 15 & 4015 & 210 & 13.0 & 991 & 87 & 10.3 & 23 & 9 & 8.3 & 19 & 30 & 6.2 \\
\hline \multirow{6}{*}{$\begin{array}{l}\text { Room } \\
\text { temperature } \\
\left( \pm 27^{\circ} \mathrm{C}\right)\end{array}$} & 0 & 0 & 0 & 1.3 & 0 & 0 & 1.3 & 0 & 0 & 1.3 & 0 & 0 & 1.3 \\
\hline & 3 & 12 & 9 & 14.8 & 6 & 43 & 11.2 & 5 & 5 & 8.6 & 2 & 10 & 6.6 \\
\hline & 6 & 1108 & 213 & 14.9 & 243 & 45 & 14.4 & 184 & 8 & 9.2 & 157 & 13 & 8.3 \\
\hline & 9 & 3757 & 570 & 17.5 & 2189 & 367 & 15.3 & 1019 & 183 & 9.9 & 892 & 17 & 8.5 \\
\hline & 12 & 7242 & 987 & 18.9 & 5568 & 460 & 17.5 & 3099 & 380 & 14.6 & 1604 & 253 & 12.5 \\
\hline & 15 & 12000 & 994 & 19.6 & 11000 & 724 & 19.3 & 5939 & 530 & 17.2 & 4477 & 500 & 13.5 \\
\hline
\end{tabular}

The quality of sausages can also be seen from the number of fungi for 15 days of storage, the lowest at refrigerator temperature $\left(4^{\circ} \mathrm{C}\right)$ and the highest at room temperature $\left(27^{\circ} \mathrm{C}\right)$, as shown in Table 3 . The Yeast Mold Count value that meets the requirements for food fit for consumption is less than $2 \times 10^{2}$ colonies/gram (BPOM 2019). The Yeast Mold Count value in sausages cased in the edible film with a $10 \%$ purslane extract concentration indicated the lowest number of fungi, both stored at refrigerator and room temperature, and has met BPOM RI standards No. 13 of 2019. Regarding this, flavonoids and alkaloids in purslane extract as antifungal compounds added to the edible film works from within the film as a barrier to contamination from the outside not to enter the packaged food product (Yudha Karlina 2013; QuirósSauceda et al. 2014).

Additionally, the higher the concentration of purslane extract added, the lower the rancidity of the sausage, as seen in the TBA value (Table 2). Sausage cased in the edible film with the addition of $10 \%$ purslane extract after 15 days of storage showed the lowest rancidity value of 6,1 $\mathrm{mg}$ at refrigerator temperature and $1,35 \times 10^{1} \mathrm{mg}$ at room temperature. Sausage stored at room temperature has a greater rancidity value than sausage stored at refrigerator temperature. The higher the temperature, the faster the microbial metabolism in the sausage, thus causing a high rancidity value. The presence of purslane extract containing antioxidant compounds in the film could inhibit the oxidative damage of sausages during storage. Apart from being a barrier for contaminants from the outside, so they do not enter packaged food products, edible films also protect food products from reactions between ingredients and oxygen, thereby inhibiting oxidative damage. The higher the concentration of purslane extract added to the edible film, the lower the TBA number. Indeed, purslane is a natural source of antioxidants (Dkhil et al. 2011). Besides, antioxidants stabilize free radicals by complementing the electron deficiency of free radicals and inhibiting the chain reaction of free radical formation (Alam et al. 2014). Based on data analysis using the Kruskal-Wallis method for 15 days of storage, the addition of purslane extract to the film significantly inhibited the growth of microorganisms and oxidative damage to sausages compared to chitosan edible films alone. Thus, the results that met the requirements were sausages stored in edible films with $10 \%$ purslane extract addition and storage for 15 days at refrigerator temperature; however, it only lasted for nine days at room temperature. Meanwhile, other results did not meet the requirements because the film with $5 \%$ extract addition only lasted for nine days at room temperature and 15 days at refrigerator temperature. Likewise, the film with the addition of $2.5 \%$ extract only lasted for six days at room temperature and 15 days at refrigerator temperature. Meanwhile, for the film without extract addition, it only lasted for three days at room temperature and 12 days at refrigerator temperature.

Lastly, the addition of purslane extract in the edible film casing did not affect the panelists' acceptance of the sausage even though the preference level was still below the film without the extract addition. Meanwhile, the panelists' responses to sausages without edible film and sausages with the edible film of $0 \%$ purslane extract had a very good value from all panelists or stated by number 5 . None of the panelists gave a score of 2 or did not like sausages with edible film with purslane extract addition. It signifies that the addition of purslane extract in the film did not change the color, aroma, taste, and texture of sausages and edible films.

Based on the study results, it can be concluded that the use of chitosan edible film with the addition of purslane extract could prevent damage to sausage casing in a film with a concentration of $10 \%$ at refrigerator temperature for 15 days and at room temperature for nine days. Thus, it has the potential to be used as a substitute for nonbiodegradable plastic packaging. 


\section{ACKNOWLEDGEMENTS}

This research was funded by Sebelas Maret University, Indonesia through "Hibah Grup Riset" with contract number 452/UN27.21/PN/2020 on behalf of Artini Pangastuti.

\section{REFERENCES}

Alam MA, Juraimi AS, Rafii MY, Abdul Hamid A, Aslani F, Hasan MM, Mohd Zainudin MA, Uddin MK. 2014. Evaluation of antioxidant compounds, antioxidant activities, and mineral composition of 13 collected purslane (Portulaca oleracea L.) accessions. Biomed Res Int. 2014:6-10. DOI: 10.1155/2014/296063.

Alves VD, Ferreira AR, Costa N, Freitas F, Reis MAM, Coelhoso IM. 2011. Characterization of biodegradable films from the extracellular polysaccharide produced by Pseudomonas oleovorans grown on glycerol byproduct. Carbohydr Polym 83 (4):1582-1590. DOI: 10.1016/j.carbpol.2010.10.010.

Anli EA, Kral AG, Damla S. 2021. Physicochemical properties and texture of ready-eat yogurt improved with dry exchange (Portulaca oleracea L.). G1da 46 (2): 229-242. DOI: $10.15237 /$ gida.GD20112

Atma Y. 2016. Total Plate Number (TPC), most likely number (apm) and total yeast mold as a simple analysis method to determine microbiological standards of posdaya processed food. Technol J 8 (2):77. DOI: $10.24853 /$ jurtek.8.2.77-83.

Bourbon AI, Pinheiro AC, Cerqueira MA, Rocha CMR, Avides MC, Quintas MAC, Vicente AA. 2011. Physico-chemical characterization of chitosan-based edible films incorporating bioactive compounds of different molecular weight. J Food Eng 106 (2): 111-118. DOI: 10.1016/j.jfoodeng.2011.03.024

BPOM. 2019. Regulation of the Food and Drug Supervisory Agency Number 13 of 2019 concerning the Maximum Limit of Microbia Contamination in Processed Food. Natl Agency Drug Food Control, Jakarta.

Campos C, Gerschenson L, Flores S. 2011. Development of edible films and coatings with antimicrobial activity. Food Bioprocess Technol 4 (6): 849-875. DOI: 10.1007/s11947-010-0434-1.

Chen D, Yao JN, Liu T, Zhang HY, Li RR, Zhang ZJ, Gu XZ. 2019 Research and application of Portulaca oleracea in the pharmaceutical field. Chinese Herbal Med 11 (2): 150-159.

Dkhil MA, Moniem AEA, Al-Quraishy S, Saleh RA. 2011. Antioxidant effect of purslane (Portulaca oleracea) and its mechanism of action. J Med Plants Res 5 (9): 1589-1593. DOI: 10.5897/JMPR.9000222.

Du YK, Liu J, Li XM, Pan FF, Wen ZG, Zhang TC, Yang PL. 2017. Flavonoids extract from Portulaca oleracea L. induce Staphylococcus aureus death by apoptosis-like pathway. Intl J Food Prop 20 (1) S534-S542. DOI: 10.1080/10942912.2017.1300812.

Estiningtyas HR, Kawiji K, Manuhara GJ. 2012. The application of maizena-edible film with addition of ginger extract as natural antioxidant in cow sausage coating. Biofarmasi J Nat Prod Biochem 10 (1): 7-16. DOI: 10.13057/biofar/f100102.

Farbod F, Kalbasi A, Moini S, Emam-Djomeh Z, Razavi H, Mortazavi A. 2013. Effects of storage time on compositional, micro-structural, rheological and sensory properties of low fat Iranian UF-Feta cheese fortified with fish oil or fish oil powder. J Food Sci Technol 52 (3): 1372-1382. DOI: 10.1007/s13197-013-1163-z.

Galus S, Arik KEA, Gniewosz M, Kraśniewska K. 2020. Novel materials in the preparation of edible films and coatings-A review. Coatings 10 (7): 674.
Gomes LP, Souza HKS, Campiña JM, Andrade CT, Silva AF, Gonçalves MP, Paschoalin VMF. 2019. Edible chitosan films and their nanosized counterparts exhibit antimicrobial activity and enhanced mechanical and barrier properties. Molecules 24 (1): 127. DOI: 10.3390/molecules24010127.

Handayani R., Christine M, Anders B. 2020. Addition of purslane leaf extract (Portulaca oleracea L.) in making jelly candy. In: Sitanggang AB, Rahayu WB, Antara NS, Santoso U, Giyatmi, Ardiansyah, Haryono A (eds.). Proceedings of the 16th ASEAN Food Conference. October 15-18, 2019. Bali, Indonesia. [Indonesian]

Helander I, Lassila E, Ahvenainen R, Rhoades J, Roller S. 2001. Chitosan disrupts the barrier properties of the outer membrane of Gramnegative bacteria. Intl J Food Microbiol 71 (2-3): 235-244. DOI: 10.1016/S0168-1605(01)00609-2.

Indradewi AF, Irnawati DHD, Hamid M. 2018. Antioxidant activity test of water extract, ethanol extract and purified ethanol extract of purslane (Portulaca oleracea Linn.) from Southeast Sulawesi with DPPH method. Appl Technol Based Local Wisdom 1 (1): 490-497.

Iranshahy M, Javadi B, Iranshahi M, Jahanbakhsh SP, Mahyari S, Hassani FV, Karimi G. 2017. A review of traditional uses, phytochemistry and pharmacology of Portulaca oleracea L. J Ethnopharmacol 205: 158172. DOI: 10.1016/j.jep.2017.05.004.

Katili S, Harsunu BT, Irawan S. 2013. Effect of concentration of glycerol plasticizer and composition of chitosan in solvents on physical properties of edible film from chitosan. Technol J 6 (1): 29-38.

Nurainy F, Rizal S, Yudiantoro. 2008. Effect of chitosan concentration on antibacterial activity with agar diffusion method (Well). J Ind Technol Agric Prod 13 (2): 117-125

Purwanti A. 2010. Analysis of the tensile strength and elongation of sorbitol plasticized chitosan plastics. Technol J 3 (2): 99-106.

Quirós-Sauceda AE, Ayala-Zavala JF, Olivas GI, González-Aguilar GA. 2014. Edible coatings as encapsulating matrices for bioactive compounds: a review. J Food Sci Technol 51 (9): 1674-1685. DOI: 10.1007/s13197-013-1246-x.

Rakhmawati EA, Musdholifah S. 2019. Quality test of jackfruit seed flour (Artocarpus heterophyllus Lamk) using dry method and wet method. Medfarm J Pharm Heal 8 (2): 55-60. DOI: 10.48191/medfarm.v8i2.19.

Sánchez-González L, Vargas M, González-Martínez C, Chiralt A, Chafer M. 2011. Use of essential oils in bioactive edible coatings: a review. Food Eng Rev 3 (1): 1-16.

Shanker N, Kumar MM, Juvvi P, Debnath S. 2019. Water absorption characteristics of ready-to-eat snacks enriched with purslane leaves. J Food Sci Technol 56 (4): 1918-1926.

Sobral PJA, Menegalli FC, Hubinger MD, Roques MA. 2001. Mechanical, water vapor barrier and thermal properties of gelatin based edible films. Food Hydrocoll 15 (4-6): 423-432. DOI: 10.1016/S0268-005X(01)00061-3.

Sultana A, Rahman K. 2013. Portulaca oleracea Linn: A global panacea with ethnomedicinal and pharmacological potential. Int J Pharm Pharm Sci 5 (2): 33-39

Youssef A, Assem F, El-Sayed S, Salama H, Abd El-Salam M. 2017. Utilization of edible films and coatings as packaging materials for preservation of cheeses. J Packag Technol Res 1 (2): 87-99. DOI: 10.1007/s41783-017-0012-3.

Yudha Karlina C. 2013. Antibacterial activity of purslane herb extract (Portulaca oleracea L.) against Staphylococcus aureus and Escherichia coli. LanternBio Biol Sci Period 2 (1): 87-93.

Zhou YX, Xin HL, Rahman K, Wang SJ, Peng C, Zhang H. 2015. Portulaca oleracea L.: A review of phytochemistry and pharmacological effects. Biomed Res Intl 2015: 925631. DOI: $10.1155 / 2015 / 925631$. 